\title{
Kütahya Bölgesi Kırmızı Topraklarından Hızlı Sinterleme Yöntemi İle Hafif Agrega Üretilmesi
}

\section{Light Weight Aggregate Production of Kütahya Region Red Soils by Rapid Sintering Method}

Geliş / Received: 20/12/2020

\author{
Mehmet Uğur Toprak ${ }^{1 *}$, Canan Mercan²
}

Revize / Revised: 19/02/2021

Kabul / Accepted: 20/02/2021

\section{ÖZ}

Bu çalışmada Çöğüler/Kütahya'dan alınan kırmızı toprak; i) gözenek oluşturmak amacıyla evsel atık arıtma çamuru, ii) sinterleme özelliklerini iyileştirmek için sodyum karbonat ve uçucu kül eklenerek hızlı sinterleme yöntemi ile hafif agrega üretilmiştir. Küçük silindirler şeklinde üretilen hafif agregaların fiziksel ve mekanik özeliklerine; kırmızı toprağın ağırlıkça \%'si olarak uçucu kül miktarı (\%12 ve \%17), presleme kuvveti (1, 3 ve $5 \mathrm{kN})$ ve sinterleme sıcaklı̆̆ının $\left(1050\right.$ ve $\left.1100^{\circ} \mathrm{C}\right)$ etkisi araştırılmıştır. Uçucu kül miktarı arttıkça basınç dayanımda artış gözlenmiştir. En yüksek hafif agrega özgül dayanımı (14,80 MPa / 0,98 ton/ $\left./ \mathrm{m}^{3}=15,10 \mathrm{kN} \cdot \mathrm{m} / \mathrm{kg}\right)$ dikkate alınarak en uygun üretim $\% 17$ oranında uçucu kül kullanımı, $1 \mathrm{kN}$ ile presleme ve $1050^{\circ} \mathrm{C}$ 'de hızlı sinterleme ile elde edilmiştir.

Anahtar Kelimeler- Kırmızı Toprak, Uçucu Kül, Hızlı Sinterleme, Hafif Agrega, Basınç Dayanımı

\begin{abstract}
Light weight aggregate was produced by rapid sintering of red soil with some admixtures; i) sewage sludge for void formation, ii) sodium carbonate and fly ash for better sintering. Little cylinders were prepared with red soil to investigate the effect of a number of variables, including the fly ash ratio by weight of red soil (12\% and 17\%), pressing force $(1,3$ and $5 \mathrm{KN})$, and rapid sintering temperature $\left(1050\right.$ and $\left.1100^{\circ} \mathrm{C}\right)$ on the physical and mechanical properties of light weight aggregate. Compressive strength increased with the increase in fly ash ratio. Considering the highest light weight aggregate specific strength $\left(14,80 \mathrm{MPa} / 0,98 \mathrm{ton} / \mathrm{m}^{3}=15,10 \mathrm{kN} . \mathrm{m} / \mathrm{kg}\right)$ the optimum production obtained with $17 \%$ of fly ash, pressing with $1 \mathrm{kN}$ and sintering at $1050^{\circ} \mathrm{C}$.
\end{abstract}

Keywords- Red Soil, Fly Ash, Rapid Sintering, Light Weight Aggregate, Compressive Strength

\footnotetext{
1*Sorumlu yazar iletişim: mugur.toprak@ dpu.edu.tr (https://orcid.org/0000-0001-5483-2871) Inşaat Mühendisliği Bölümü, Kütahya Dumlupınar Üniversitesi 2̇̉letişim: cnanmercan@gmail.com (https://orcid.org/0000-0002-8366-3576)

Inşaat Mühendisliği Bölümü, Kütahya Dumlupınar Üniversitesi
} 


\section{GíRiş}

Beton taşıdığı yüke oranla ağır bir taşıyıcı malzemedir. Yapısal hafif betonun, yapı ölü yüklerini ve dolayısıyla deprem etkilerini azaltması, daha yüksek yangın direnci, 1sı ve ses yalıtımı, işçilik ve zamandan tasarruf sağlaması nedenleriyle, özellikle çok katlı ve büyük açıklıklı yapılarda kullanımı önem kazanmaktadır [1,2]. Akdeniz bölgesi kırmızı toprakları (Terra Rossalar) temelini oluşturan dirençsiz kalker kayalarının yüksek iç drenaj ve nötr pH koşulları sunan akdeniz ikliminde aşınması sonucu oluşurlar [3]. Akdeniz bölgesi kırmızı toprakları hematit vb. demir oksitler, kaolin, mika, vermükülit, quartz ve az miktarda feldispatlardan oluşmaktadır [4]. Quartz sinterlenen cisimlerin deformasyon ve büzülmesini dengelerken, sodyumca zengin feldispatlar sinterlenen cismin sağlamlaşmasını sağlayan ve porozitesini belirleyen yarı sıvı fazı oluştururlar [5-7].

Avrupa'da aktüel deniz dibi killeri ile acı su killeri, rüzgar erozyonuna bağlı Lös killeri, Jura killeri, Devonien yaşlı killişistler ve şifertonlar teknik bakımdan değerlendirilebilecek ölçüde genleşme özelliğine sahip hammaddeler olarak tespit edilmiştir. Bunların $\mathrm{SiO}_{2}$ oranı $\% 48-69, \mathrm{Al}_{2} \mathrm{O}_{3}$ oranı $\% 15-22, \mathrm{Fe}_{2} \mathrm{O}_{3}$ oranı $\% 5-10$, $\mathrm{CaO}+\mathrm{MgO}$ oranı \%3-7, alkali oranı 3-6 ve ateş zayiatı \%5-15 arasında değişmektedir [8]. Lee [9] \%60 kırmızı kil, \%40 kum tozu karışımına gözenek oluşturmak amacı ile kütlece \%2-6 arasında değişen amorf karbon veya gazyağı ekleyerek hızlı sinterleme yöntemi ile hafif agrega üretmiştir. Üretilen hafif agregaların; agrega yüzey alanı/hacim oranı küçüldükçe (numune boyutları büyüdükçe bu oran küçülmektedir) genleşme miktarlarının önemli ölçüde arttığını göstermiştir. Koçkal ve Özturan [10] $1100^{\circ} \mathrm{C}^{\prime}$ de 1 saat pişirdikleri hafif uçucu küllü agreganın basınç dayanımını $5,1 \mathrm{MPa}$, birim hacim ağırlığıı $1,51 \mathrm{~g} / \mathrm{cm}^{3}$ ve ağırlıkça su emme oranını $\% 18,4$ olarak bulmuşlardır. T.Y. Lo ve ark. [11] sinterlenmiş yüksek karbonlu uçucu kül-kil karışımı kullanarak ürettiği hafif betonlarda sırasıyla $56 \mathrm{MPa}, 2,9 \mathrm{MPa}, 19,7 \mathrm{GPa}$ ve $1,74 \mathrm{t} / \mathrm{m}^{3} 28$ günlük basınç dayanımı, çekme dayanımı, elastisite modülü ve birim hacim ağıllık değerleri elde etmişlerdir.

Avrupa'da 2007 yılında evsel atık arıtma çamuru (EAAÇ) miktarı 10 milyon ton olarak hesaplanmıştır [12,13]. Çevre problemlerine neden olan EAAÇ hiçbir işlem yapmadan tuğla üretiminde kullanılabilmektedir [14]. Hafif agregaların yapı malzemeleri ve betonda kullanımı; bina ağırlı̆ıını ve dolayısıyla depremde binayı etkileyecek kuvvetleri azaltmakta, ısı ve ses yalıtımını artırmaktadır. Yüksek lisans tez çalışmasından [15] elde edilen teknik bulgular kapsamında yürütülen bu çalışmada Çöğürler/Kütahya'dan alınan kırmızı topraktan (KT), boşluk oluşturmak ve sinterleme özeliklerini iyileştirmek amacıyla çeşitli katkılar eklenerek hızlı sinterleme yöntemi ile hafif agrega üretilmiştir. Üretilen hafif agregaların fiziksel ve mekanik özeliklerine uçucu kül (UK) miktarı, presleme kuvvetinin ve sinterleme sıcaklığının etkisi araştırılmıştır.

\section{MALZEME VE YÖNTEM}

Çögürler/Kütahya'dan alınan kırmııı toprak (KT) halkalı değirmende 2 dk öğütülmüştür. Özgül yüzey (Blaine) değeri $2700 \mathrm{~cm}^{2} / \mathrm{gr}$ ölçülmüştür. $3270 \mathrm{~cm}^{2} / \mathrm{gr}$ blaine değerindeki UK Seyitömer Termik Santrali Kütahya'dan alınmıştır. KT [15] ve UK'nın [16] kimyasal ve özelikleri Tablo 1, kullanılan malzemelerin görselleri Şekil 1'de verilmiştir. Tablo 1'den KT'nin oksit içeriğinin genleşen killerin oksit içeriklerine yakın olduğu, $\mathrm{CaO}+\mathrm{MgO}$ içeriğinin UK kullanılarak artırılabileceği görülmektedir. Detsan Kimya San. ve Tic. Ltd. Şti./Eskişehir'den temin edilen sodyum karbonat (SK) \% 99 saflıktadır. Eskişehir, İstanbul, Bilecik, Bursa, Ankara gibi yakın illerin Belediye Evsel Atık Su Arıtma Tesislerinden Söğüt Toprak Madencilik Sanayi A.Ş./Bilecik tarafından temin edilen ve çalışmamızda hafif agrega üretiminde gözenek oluşturmak için kullandığımız 190805 kodlu EAAÇ \%79 su ile \%21 organik maddeden oluşmaktadır.

Tablo 1. Kırmızı toprak ve uçucu külün kimyasal kompozisyonu

\begin{tabular}{|c|c|c|c|c|c|c|c|c|c|c|c|c|c|}
\hline & $\begin{array}{c}\text { Oksit } \\
\text { içeriği }\end{array}$ & $\mathrm{SiO}_{2}$ & $\mathbf{A l}_{2} \mathbf{O}_{3}$ & $\mathrm{Na}_{2} \mathrm{O}$ & $\mathbf{K}_{2} \mathbf{O}$ & $\mathrm{Fe}_{2} \mathrm{O}_{3}$ & $\mathrm{CaO}$ & MgO & MnO & $\mathrm{TiO}_{2}$ & Cl & $\mathrm{SO}_{3}$ & ${ }^{\mathrm{a}} \mathbf{K K}$ \\
\hline \multirow{2}{*}{$\begin{array}{c}\text { Kütlece } \\
\%\end{array}$} & KT & 56,07 & 15,98 & 0,14 & 1,93 & 6,52 & 1,91 & 1,27 & 0,11 & 0,57 & 0,06 & 0,05 & 15,25 \\
\hline & UK & 54,49 & 20,58 & 0,65 & 2,01 & 9,27 & 4,26 & 4,48 & - & - & 0,0058 & 0,52 & 3,01 \\
\hline
\end{tabular}

a*: Kızdırma kaybı. 


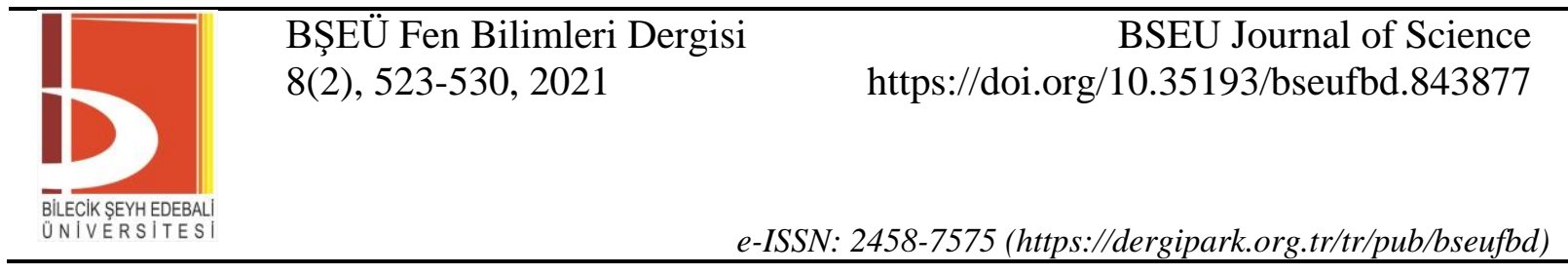

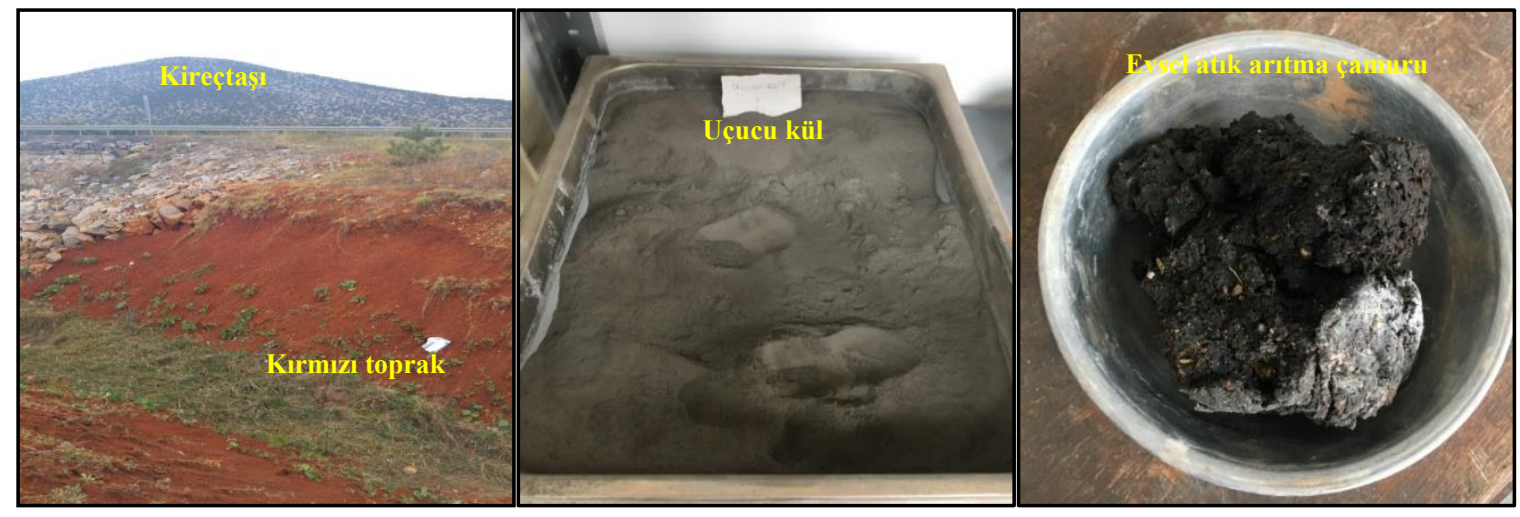

Şekil 1. Kırmızı toprak, uçucu kül ve evsel atık arıtma çamuru

Şekil 2'de X-1şınları difraktogramı verilen KT'de hekzagonal formda kuvars $\left(\mathrm{SiO}_{2}\right)$, ortorombik formda tridimit $\left(\mathrm{SiO}_{2}\right)$ ve hekzagonal formda hematit $\left(\mathrm{Fe}_{2} \mathrm{O}_{3}\right)$ bulunmaktadır. UK'da başta camsı faz olmak üzere, kuvars, mullit, magnezyoferrit, hematit kristalleri ve minör olarak alkali feldispatlar bulunmaktadır [16].

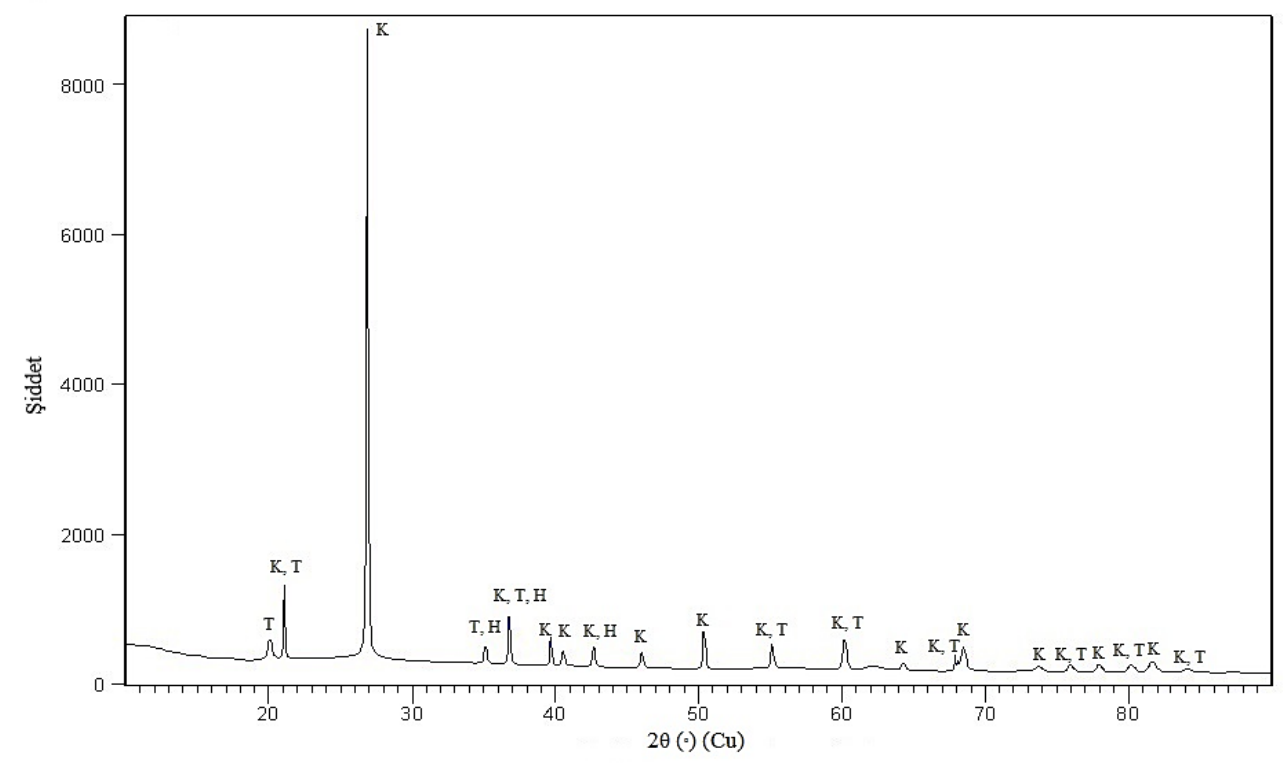

Şekil 2. Kırmızı toprak mineralojik bileşimine ait X-1şınları difraktogramı (K: kuvars, T: tridimit, H: hematit)

KT, sinterleme özeliklerini iyileştirmek için UK ve SK, gözenek oluşturmak amaciyla EAAÇ (suda çözülerek eklenmiştir) ve su homojen bir şekilde karıştııılarak elde edilen hamur silindir kalıpta (Şekil 3) preslenerek yaklaşık $14 \mathrm{~mm}$ çap ve yüksekliğinde 12 seri, toplam 36 silindir numune üretilmiştir. Hızlı sinterleme aşamasında yüksek buhar basıncından dolayı çatlama, patlama vb olmaması için laboratuvar koşullarında (20 $\pm 2{ }^{\circ} \mathrm{C}, 50 \pm 10$ bağıl nem) 24 saat bekletilerek önkurutma uygulanan ve bu şekilde hem dayanımları bir miktar artırılan hem de su miktarları azaltılan numuneler kül firınında (Şekil 4) 4 dakika sinterlendikten sonra havada soğutulmuştur. Üretilen hafif agregaların seri kodları, karışım oranları (KT'ın ağırlıkça \%'si olarak), presleme kuvveti (PK) ve sinterleme sıcaklıkları (SS) Tablo 2'de gösterilmektedir. 


\begin{tabular}{|c|c|c|}
\hline & $\begin{array}{l}\text { BŞEÜ Fen Bilimleri Dergisi } \\
8(2), 523-530,2021\end{array}$ & $\begin{array}{r}\text { BSEU Journal of Science } \\
\text { https://doi.org/10.35193/bseufbd.843877 }\end{array}$ \\
\hline $\begin{array}{l}\text { IKSEYHEDEBALI } \\
\text { VERSITES| }\end{array}$ & & 2458-7575 (https://dergipark.org.tr/tr/pub/bseufbd) \\
\hline
\end{tabular}

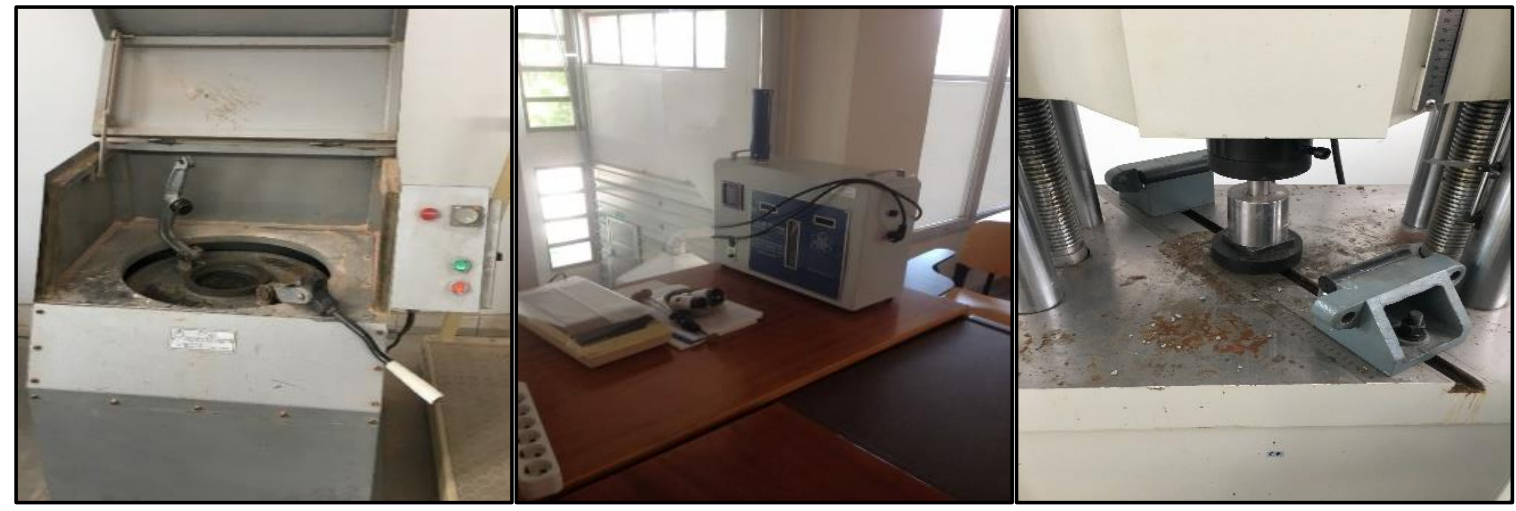

Şekil 3. Halkalı değirmen, blaine cihazı, karışımların silindir kalıpta farklı kuvvetler ile preslenmesi

Tablo 2. Hafif agrega serilerinin karışım ve üretim değişkenleri

\begin{tabular}{|c|c|c|c|c|c|c|}
\hline Seri kodu & $*$ SK $(\%)$ & *EAAÇ (\%) & $* \mathbf{U K}(\%)$ & $* \mathbf{S U}(\%)$ & PK (kN) & SS $\left({ }^{\circ} \mathrm{C}\right)$ \\
\hline UK12-1-BE & \multirow{6}{*}{8} & \multirow{6}{*}{5} & \multirow{6}{*}{12} & \multirow{6}{*}{30} & 1 & 1050 \\
\hline UK12-1-BY & & & & & 1 & 1100 \\
\hline UK12-3-BE & & & & & 3 & 1050 \\
\hline UK12-3-BY & & & & & 3 & 1100 \\
\hline UK12-5-BE & & & & & 5 & 1050 \\
\hline UK12-5-BY & & & & & 5 & 1100 \\
\hline UK17-1-BE & \multirow{6}{*}{8} & \multirow{6}{*}{5} & \multirow{6}{*}{17} & \multirow{6}{*}{30} & 1 & 1050 \\
\hline UK17-1-BY & & & & & 1 & 1100 \\
\hline UK17-3-BE & & & & & 3 & 1050 \\
\hline UK17-3-BY & & & & & 3 & 1100 \\
\hline UK17-5-BE & & & & & 5 & 1050 \\
\hline UK17-5-BY & & & & & 5 & 1100 \\
\hline
\end{tabular}

* Değerler KT’ın ağırlıkça \%'si olarak verilmektedir.

Üretilen hafif agregalar üzerinde hacimce genleşme (HG), TS EN 1097-6'ya [17] göre tane yoğunluğu (TY) ve ağırlıkça su emme (ASE) ve harç presinde basınç dayanımı (BD) (yükleme hızı: 0,6 MPa/sn) deneyleri yapılmıştır. Ayrıca UK12-3-BE ve UK17-3-BE serisi hafif agregaların optik mikroskop görüntüleri alınmıştır.

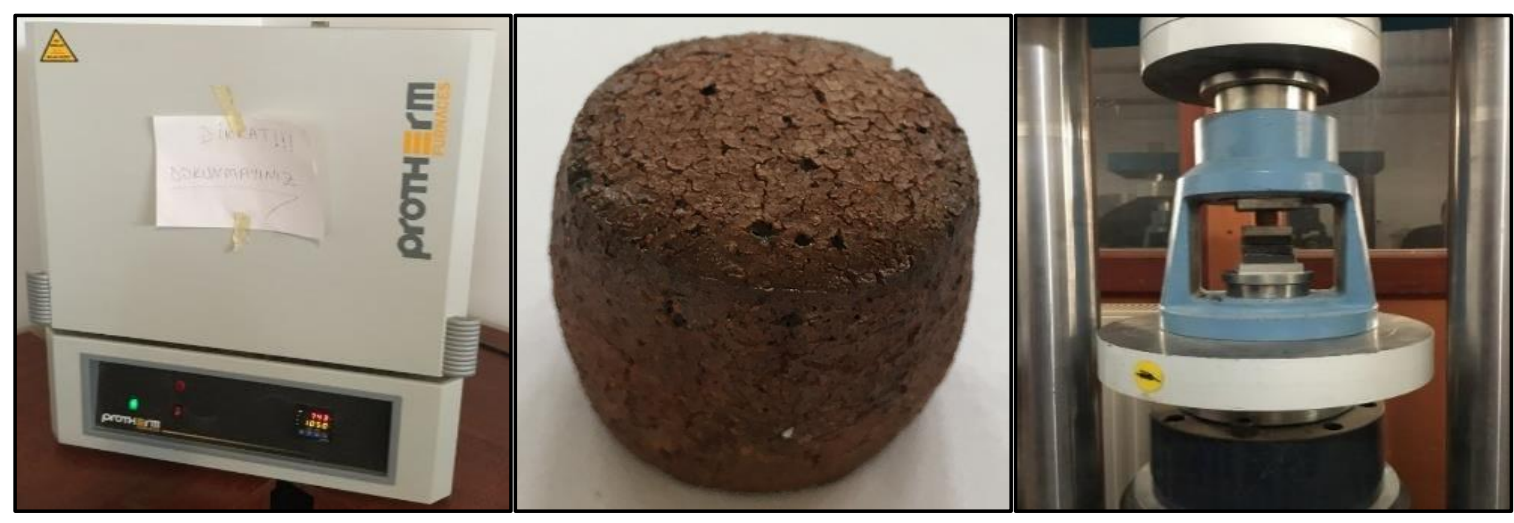

Şekil 4. Protherm Furnaces marka kül firını, firından çıkan hafif agrega, harç presi 


\section{DENEYSEL ÇALIŞMA SONUÇLARI}

Tablo 3'ten üretilen hafif agregaların ağırlıkça su emme (ASE) miktarlarlarının ilk 5 dakikada yaklaşık \% 11 'e kadar yükselebildiği, 24 saatlik ASE değerlerinin \%12-19 aralığında olduğu görülmektedir. Hızlı sinterleme sıcaklığ $1050^{\circ} \mathrm{C}$ 'den $1100^{\circ}$ C'ye çıktığında ASE değerlerinin azalmasının, daha iyi sinterlenmeden dolayı kabuk yapısının daha boşluksuz olmasından kaynaklandığı düşünülmektedir.

Tablo 3. Hafif agrega serilerinin su emme deney sonuçları

\begin{tabular}{|c|c|c|c|c|c|c|c|}
\hline \multirow{2}{*}{ Seri kodu } & \multirow{2}{*}{ PK (kN) } & \multirow{2}{*}{$\mathrm{SS}\left({ }^{\circ} \mathrm{C}\right)$} & \multicolumn{5}{|c|}{$\operatorname{ASE}(\%)$} \\
\hline & & & $5 \mathbf{d k}$ & $10 \mathrm{dk}$ & $15 \mathrm{dk}$ & $30 \mathbf{d k}$ & 24 saat \\
\hline UK12-1-BE & 1 & 1050 & 8 & 9,71 & 10,28 & 11,14 & 15,42 \\
\hline UK12-1-BY & 1 & 1100 & 5,35 & 5,91 & 6,76 & 7,88 & 13,52 \\
\hline UK12-3-BE & 3 & 1050 & 10,25 & 11,39 & 12,25 & 14,24 & 19,08 \\
\hline UK12-3-BY & 3 & 1100 & 5,71 & 7,14 & 7,42 & 8,85 & 13,86 \\
\hline UK12-5-BE & 5 & 1050 & 7,42 & 8,57 & 9,71 & 11,42 & 16,57 \\
\hline UK12-5-BY & 5 & 1100 & 10,63 & 11,78 & 12,35 & 13,21 & 18,96 \\
\hline UK17-1-BE & 1 & 1050 & 9,85 & 11,54 & 11,83 & 12,11 & 17,46 \\
\hline UK17-1-BY & 1 & 1100 & 8,52 & 8,8 & 9,65 & 10,79 & 14,48 \\
\hline UK17-3-BE & 3 & 1050 & 9,11 & 10,22 & 11,32 & 11,87 & 16,02 \\
\hline UK17-3-BY & 3 & 1100 & 6,01 & 9,56 & 9,83 & 10,38 & 14,35 \\
\hline UK17-5-BE & 5 & 1050 & 8,68 & 8,96 & 9,8 & 10,64 & 15,12 \\
\hline UK17-5-BY & 5 & 1100 & 5,29 & 6,34 & 7,14 & 7,93 & 12,16 \\
\hline
\end{tabular}

Hacim genleşmesi 1050 ve $1100^{\circ} \mathrm{C}$ ' de sinterlenen hafif agregalarda sırasılyla \% 53-73 ve \% $130-163$ aralığındadır (Şekil 5). Hacim genleşmesi; UK12 serilerinde artan presleme kuvveti ile artarken, UK17 serilerinde azalmaktadır. UK miktarı arttıkça; düşük $(1 \mathrm{kN})$ presleme kuvveti için hacim genleşmesi artarken, yüksek $(5 \mathrm{kN})$ presleme kuvveti için azalmaktadır. Bu durum UK'nın küresel şekilli olması ve KT'ye göre daha yüksek blaine değerine sahip olmasından dolayı, hammaddelerin sıkıştırılabilirliğini ve taneler arası boşluk yapısını etkilemesinden kaynaklandığı düşünülmektedir.

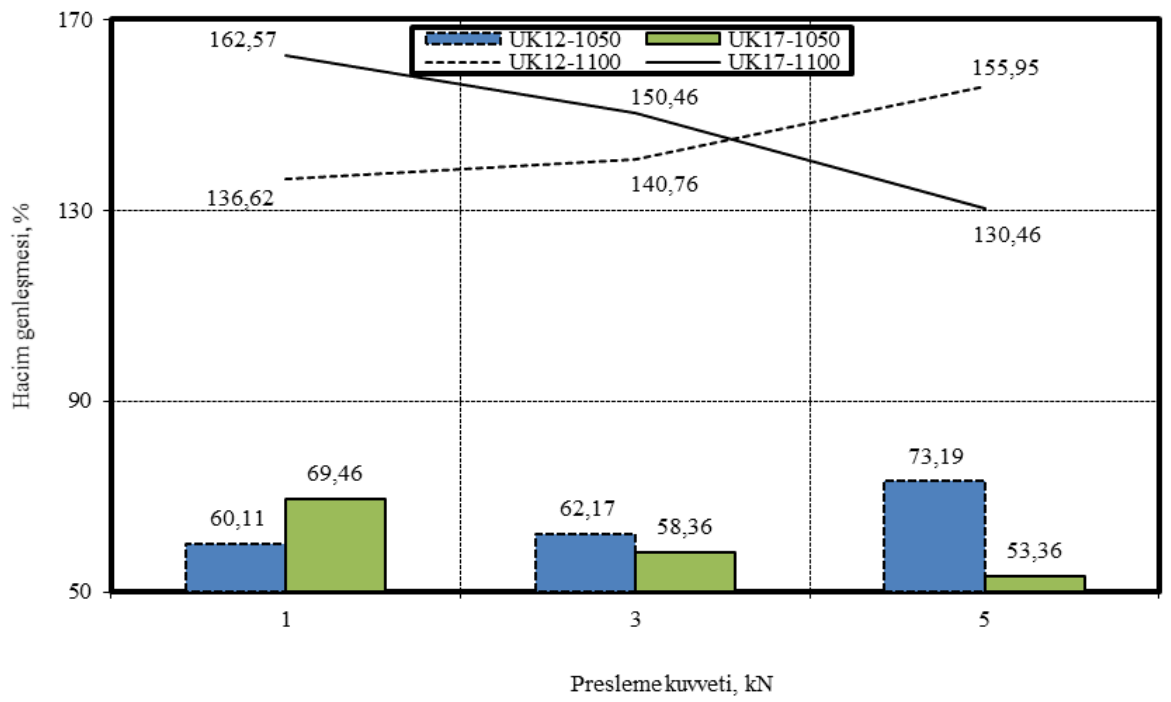

Şekil 5. Hafif agregaların hacim genleşmeleri 
Bütün hafif agregalar için hızlı sinterleme süresi 4 dakikadır. Ancak yüksek sıcaklıklarda hafif agrega dış yüzeyindeki taneler daha hızlı birleşerek boşlukları kapatmakta ve böylece hafif agrega kabuğu daha kısa sürede oluşmaktadır. EAAÇ’nin yanmasıyla oluşan gaz dışarıya çıkamayıp henüz plastik kıvamdaki kabuğu daha uzun süre şişirerek hafif agregayı daha fazla genleştirmektedir. Şekil 6'dan hacim genleşmelerinden ve yanma sonucu kütle kaybından dolayı birim hacim ağırlık değerlerinin önemli ölçüde düştüğü görülmektedir.

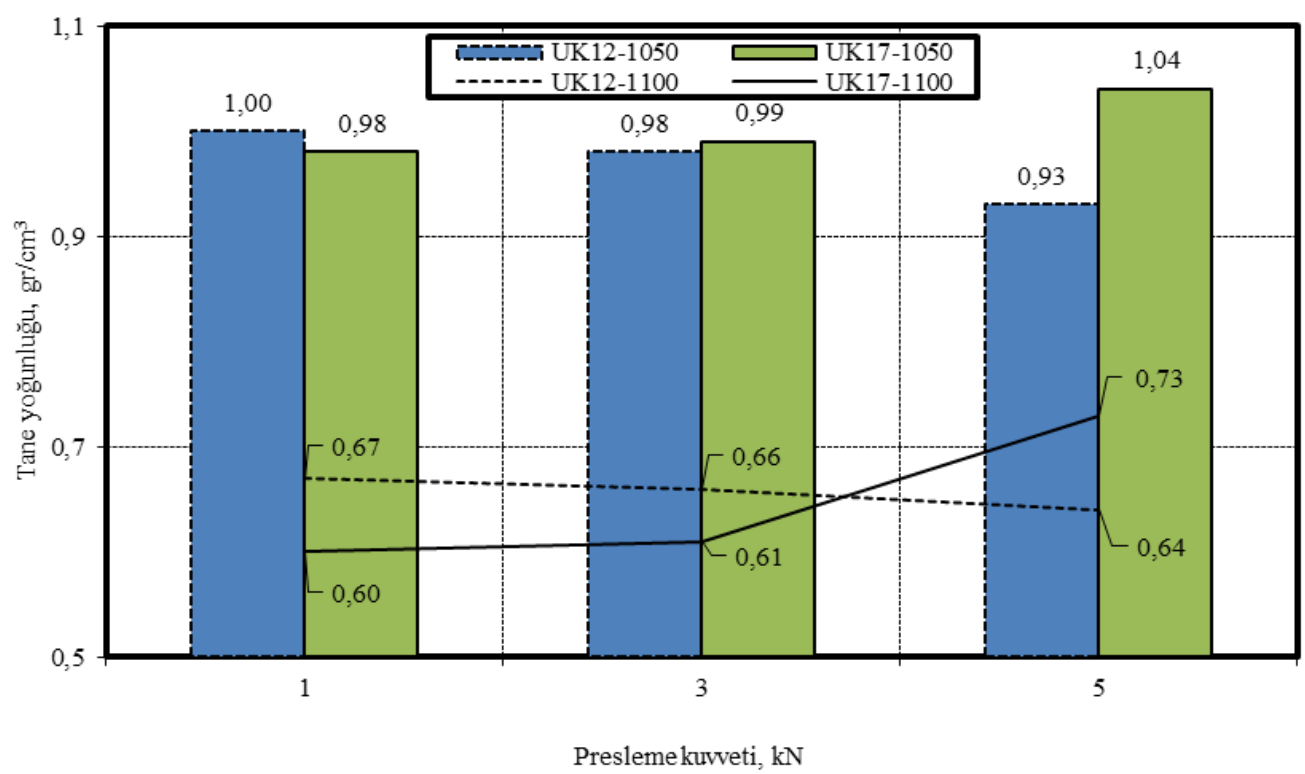

Şekil 6. Hafif agregaların tane yoğunlukları

Şekil 7'de UK12 ve UK17 serilerinde $1050^{\circ} \mathrm{C}^{\prime}$ de pişirilen hafif agrega dayanımlarının $1100^{\circ} \mathrm{C}$ 'de sinterlenenlerden daha yüksek olduğu görülmektedir. UK17 serilerinde bu fark daha belirgindir. Sicaklık artışı hafif agregaları dayanımı düşürmektedir. Presleme kuvvetinin artması UK12 serilerinde $1050^{\circ} \mathrm{C}$ 'de üretilen hafif agregalarda basınç dayanımlarını artırırken $1100^{\circ} \mathrm{C}$ için düşürmüştür. UK17 serilerinde ise presleme kuvvetinin artması bütün sıcaklıklar için basınç dayanımlarını düşürmüştür. Sıvı faz oluşumunu destekleyerek hafif agregayı sağlamlaştırması nedeniyle uçucu kül miktarı arttığında hafif agregaların basınç dayanımlarında artış gözlemlenmektedir. $\mathrm{Bu}$ artış $1 \mathrm{kN}$ ile ile preslenen ve $1050^{\circ} \mathrm{C}$ 'de üretilen hafif agregalarda çok daha belirgindir.

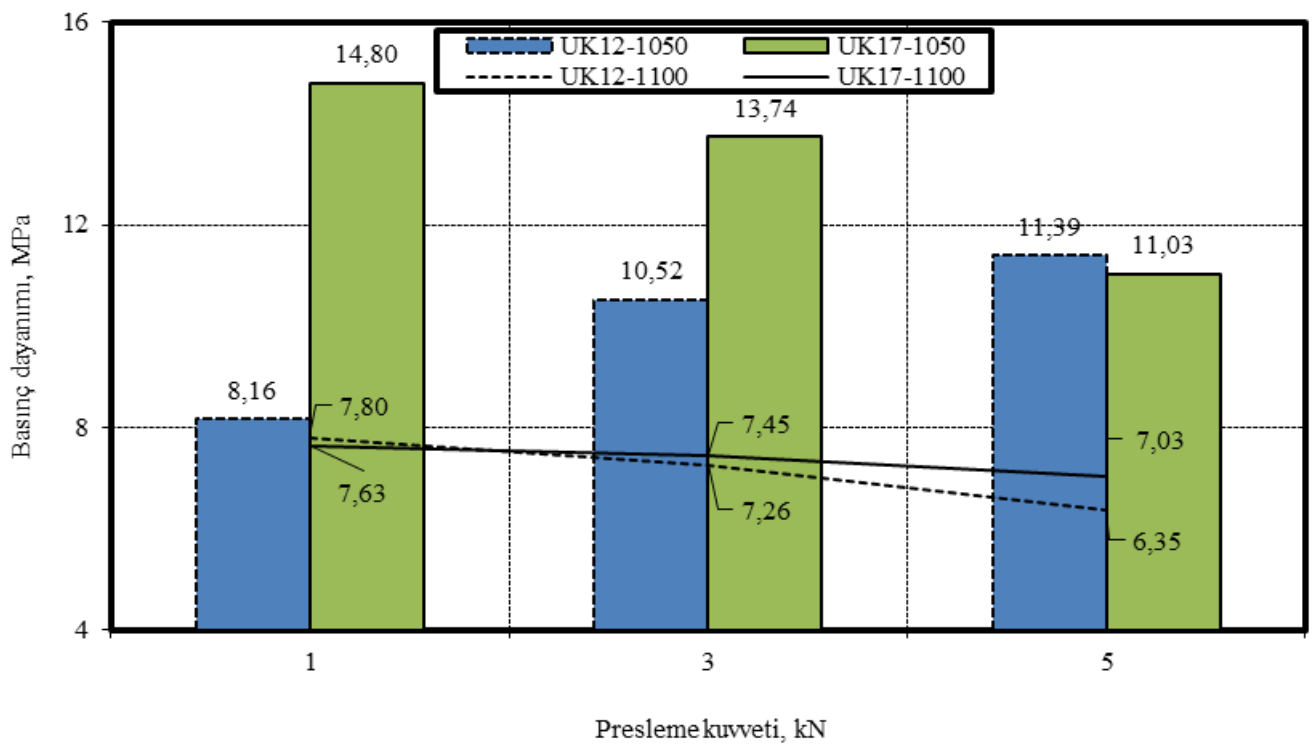

Şekil 7. Hafif agregaların basınç dayanımları 
Şekil 8'de UK17-3-BE numunesinde UK12-3-BE numunesine göre daha kalın ve sağlam kabuk oluşumu meydana geldiği görülmektedir. Ayrıca boşlukların daha küçük olduğu ve daha homojen dağıldığı gözlenmektedir. UK17-3-BE'nin basınç dayanımı yapılan gözlemlere paralel bir şekilde UK12-3-BE'den \% 30 daha yüksektir.

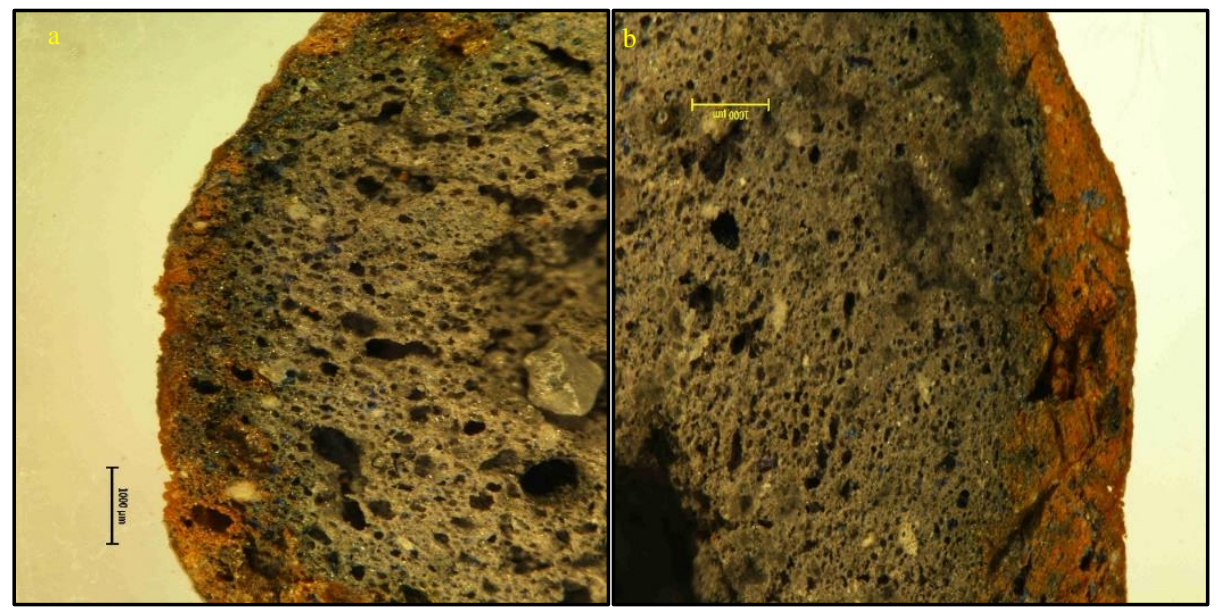

Şekil 8. a) UK12-3-BE ve b) UK17-3-BE numunelerinin optik mikroskop görüntüleri

\section{SONUÇ VE ÖNERÍLER}

Ön çalışmalarda sadece kil, uçucu kül ve evsel atıkla oluşturulan numunelerde hızlı sinterlemenin başarılı olmadığı görülmüştür. Sinterlemede sıvı faz oluşumunu desteklemek amacıyla $\mathrm{Na}_{2} \mathrm{CO}_{3}$ kullanılmıştır. Hafif agregalarda $1100^{\circ} \mathrm{C}^{\prime}$ ye kadar hızlı sinterleme sürecinde sıvı fazda köpürme oluşmadığ gözlemlenmiştir. Hacim genleşmesi 1050 ve $1100^{\circ} \mathrm{C}^{\prime}$ de sinterlenen agregalarda sirasıyla $\% 53-\% 73$ ve $\% 130-\% 163$ aralığındadır. Tane yoğunluğu 1050 ve $1100^{\circ} \mathrm{C}^{\prime}$ de sinterlenen agregalarda sirasiyla $0,93-1,04 \mathrm{gr} / \mathrm{cm}^{3}$ ile $0,60-0,73 \mathrm{gr} / \mathrm{cm}^{3}$ aralığındadır. Üretilen hafif agregalarda uçucu kül miktarı arttıkça basınç dayanımının arttğı̆, bu etkinin $1050^{\circ} \mathrm{C}$ 'de sinterlenen serilerde çok daha belirgin olduğu görülmüştür. En yüksek hafif agrega özgül dayanımı (14,80 MPa / $0,98 \mathrm{ton} / \mathrm{m}^{3}=15,10 \mathrm{kN} \cdot \mathrm{m} / \mathrm{kg}$ ) dikkate alınarak en uygun üretim $\% 17$ oranında uçucu kül kullanımı, $1 \mathrm{kN}$ ile presleme ve $1050^{\circ} \mathrm{C}^{\prime}$ de hızlı sinterleme ile elde edilmiştir. Hafif agreganın genleşme miktarı, boşluk yapısı ve basınç dayanımını; sinterlenen malzemelerin mineralojik yapısı, tane boyutları, hızlı sinterleme süre ve sıcaklı̆g önemli oranda etkilemektedir. Bu etkilerin termal ve mineralojik analiz yöntemleri, elektron mikroskopu kullanarak daha kapsamlı araştırılması önerilmektedir.

\section{TEŞEKKÜR}

Yazarlar, Söğüt Toprak Madencilik Sanayi A.Ş’ye evsel atık arıtma çamuru temini ve hafif agrega üretiminde bilgi ve tecrübe paylaşımlarından dolayı teşekkür ederler.

\section{KAYNAKLAR}

[1] Kalpana, M. \& Tayu, A. (2020). Light weight steel fibre reinforced concrete: A review. Materials Today: Proceedings, 22 (3), 884-886.

[2] Costa, H. Carmo, R. N. F. \& Júlio E. (2018). Influence of normal stress and reinforcement ratio on the behavior of LWAC interfaces. Construction and Building Materials, 192, 317-329.

[3] Vingiani, S. Di Iorio, E. Colombo, C. \& Terribile, F. (2018). Integrated study of Red Mediterranean soils from Southern Italy. Catena, 168, 129-140.

[4] Torrent, J. (2005). Mediterranean soils. In: Hillel, D. Ed., Encyclopaedia of Soils in the Environment, 2, Elsevier Academic Press, Oxford, 418-427.

[5] Diella, V. Adamo, I. Pagliari, L. Pavese, A. \& Francescon, F. (2015). Effects of particle size distribution and starting phase composition in Na-feldspar/kaolinite system at high temperature. Journal of the European Ceramic Society, 35 (4), 1327-1335.

[6] Das, S. K. \& Dana K. (2003). Differences in densification behaviour of K- and Na-feldspar-containing porcelain bodies. Thermochim Acta, 406, 199-206. 
[7] Alves, H. J. Melchiades, F. G. \& Boschi, A. O. (2012). Effect of feldspar size on the porous microstructure and stain resistance of polished tiles. Journal of the European Ceramic Society, 32, 2095-2102.

[8] Seyhan, İ. (2001). Genleşen Killer. DPT Sekizinci Beş Yıllık Kalkınma Planı Madencilik ÖİK Raporu Endüstriyel Hammaddeler Alt Komisyonu Yapı Malzemeleri III (Ponza-Perlit-Vermikülit-FlogopitGenleşen Killer) Çalışma Grubu Raporu, DPT: 2617 - ÖIKK: 628, 69-72.

[9] Lee, K. G. (2016). Bloating Mechanism of Lightweight Aggregate with the Size. Journal of the Korean Ceramic Society, 53-2, 241-245.

[10] Koçkal, N. U. \& Özturan, T. (2011). Durability of Lightweight Concretes with Lighweight Fly Ash Aggregates. Construction and Building Materials, 25(3), 1430-1438.

[11] Lo, T. Y., Cui, H., Memon, S. A. \& Noguchi, T. (2016). Manufacturing of sintered lightweight aggregate using high-carbon fly ash and its effect on the mechanical properties and microstructure of concrete. Journal of Cleaner Production, 112 (1), 753-762.

[12] Mininni, G., Blanch, A.R., Lucena, F. \& Berselli, S. (2015). EU policy on sewage sludge utilization and perspectives on new approaches of sludge management. Environmental Science and Pollution Research, 22, 7361-7374.

[13] IPTS (Institute for Prospective Technological Studies). (2014) End-ofwaste criteria for biodegradable waste subjected to biological treatment (compost \& digestate): Technical proposals. Final report 2013, European Commission, JRC scientific and policy reports, ISBN 978-92-79-35062-7 (pdf), available at: http://ftp.jrc.es/ EURdoc/JRC87124.pdf.

[14] Areias, I. O. R., Vieira, C. M. F., Colorado, H. A., Delaqua, G. C. G. \& Azevedo, A. R. G. (2020). Could city sewage sludge be directly used into clay bricks for building construction? A comprehensive case study from Brazil. Journal of Building Engineering, 31, 101374.

[15] Mercan, C. (2020). Alkaliler, Uçucu Kül ve Sinterlemenin Hafif Agrega Üretimine Etkisi. Yüksek Lisans Tezi, Kütahya Dumlupınar Üniversitesi, Fen Bilimleri Enstitüsü, Kütahya.

[16] Türker, P., Erdoğan, B., Katnaş, F. \& Yeğinobali, A. (2009). Türkiye'deki Uçucu Küllerin Siniflandirilmasi ve Özellikleri. Türkiye Çimento Müstahsilleri Birliği. Ar-Ge, Y03.03, 109.

[17] TS EN 1097-6. (2013). Agregaların Mekanik ve Fiziksel Özellikleri Için Deneyler Bölüm 6: Tane Yoğunluğu ve Su Emme Oranının Tayini. Türk Standartları Enstitüsü, Ankara. 